\title{
Biofertilizante agrobio: Uma alternativa no controle da mancha bacteriana em mudas de pimentão (Capsicum annuum l.)
}

\author{
Biofertilizer agrobio: An alternative in the control of leaf spot in pepper \\ seedlings (capsicum annuum l.)
}

\author{
Cláudia Sayão Ramirez Deleito ${ }^{1}$ Margarida Goréte Ferreira do Carmo ${ }^{2}$ \\ Maria do Carmo de Araújo Fernandes ${ }^{3}$ Antônio Carlos de Souza Abboud ${ }^{4}$
}

\section{RESUMO}

Agrobio é um biofertilizante líquido fabricado à base de esterco bovino, água, melaço e sais minerais, que são submetidos a um processo de fermentação à temperatura ambiente por 56 dias em recipientes abertos. Este produto tem sido largamente utilizado com sucesso por agricultores orgânicos e convencionais em todo o estado do Rio de Janeiro, no controle de várias enfermidades vegetais em diferentes culturas. Em bioensaios realizados em casa de vegetação, observou-se uma ação bacteriostática equivalente a de produtos químicos comerciais contra Xanthomonas campestris pv. vesicatoria em mudas de pimentão (Capsicum annuum L.), numa concentração de $5 \%$. Nos bioensaios in vitro, onde foram testadas as concentrações de 2, 510 e 50\% do Agrobio comercial, observouse que, a partir da concentração de $5 \%$, ocorreu um nível satisfatório de inibição do crescimento bacteriano, apesar deste ter sido inferior ao obtido com o uso de sulfato de cobre e sulfato de estreptomicina.

Palavras-chave: antibiose, agroecologia, cultura do pimentão (Capsicum annuum L.)

\section{ABSTRACT}

Agrobio is a liquid biofertilizer made from fresh cattle manure, water, molasses and minerals, which are fermented under room temperature in open containers for 56 days. This product has been widely used by organic and conventional farmers throughout Rio de Janeiro State for the control of several plant pathogens in different crops. Greenhouse bioassays showed that Xanthomonas campestris pv. vesicatoria in pepper (Capsicum annuum) transplants were satisfactorily controlled when concentration of Agrobio was $5 \%$. In vitro assays using concentrations of 2, 5, 10 and $50 \%$ showed that concentrations above $5 \%$ were capable of controlling the pathogen. However, the levels of control of Agrobio were lower than those of copper sulfate and streptomycin sulfate.

Key words: antagonistic effect, agroecology, green pepper tillage (Capsicum annuum L.).

\section{INTRODUÇÃO}

Na Região Sudeste, um dos biofertilizantes mais utilizados em várias culturas é o Agrobio (FERNANDES, 2000), produzido e pesquisado na Estação Experimental de Itaguaí (EEI) da PESAGRORIO, em Seropédica, RJ. Este produto é usado como fertilizante foliar e também como meio de controle de algumas doenças em mudas de hortaliças folhosas, ornamentais e frutíferas em geral. O Agrobio (FERNANDES, 2000) é obtido da atividade de microrganismos em sistema aberto, em substrato composto pela mistura de água, esterco bovino fresco, melaço, leite e sais minerais. Após 56 dias, transforma-se numa complexa mistura de vitaminas, hormônios, antibióticos e outros componentes (FERNANDES, 2000), que, ao ser absorvida pelas plantas, acredita-se que atue como fonte suplementar de nutrientes, aumentando sua resistência natural ao ataque de pragas e patógenos, além de exercer ação direta sobre os fitoparasitas devido à presença na calda de substâncias tóxicas aos mesmos (PINHEIRO \& BARRETO, 1996). Como no Agrobio há uma comunidade microbiana composta por fungos unicelulares e filamentosos e bactérias, a ação pode ser, ainda, resultante da intensa atividade destes microrganismos, garantida pelas aplicações freqüentes do produto. Quando aplicado no solo, propicia a melhoria de características físicas como densidade aparente, porosidade, aeração e fertilidade e estimulando suas atividades biológicas (SANTOS, 1992). Apesar dos benefícios creditados ao produto, há poucos relatos quantificando ou explicando seus efeitos.

\footnotetext{
'Aluno de Pós-graduação em Fitotecnia, Universidade Federal Rural do Rio de Janeiro (UFRRJ), Instituto de Veterinária, Departamento de Microbiologia e Imunologia Veterinária, 23890-000, Seropédica, RJ. E-mail: claudiasayao@aol.com. Autora para correspondência. ${ }^{2}$ Engenheiro agrônomo, Professor Doutor do Departamento de Fitotecnia, UFRRJ.

${ }^{3}$ Biólogo, Pesquisador da Pesquisa Agropecuária (PESAGRO-RIO), Estação de Seropédica.

${ }^{4}$ Engenheiro agrônomo, Professor, Doutor do Departamento de Fitotecnia, UFRRJ.
} 
No cultivo protegido do tomateiro sob manejo orgânico conduzido na EEI-PESAGRO, observou-se que pragas e doenças foram mantidas sobre controle mediante o uso do Agrobio e de adubação orgânica, sendo a produção final equivalente às obtidas com o uso de insumos químicos (FERNANDES et al., 2000). Pulverizações com Agrobio em mudas de maracujazeiro amarelo (Passiflora edulis $f$. flavicarpa L.) proporcionaram maior altura, número de ramos e de frutos e deixaram a cultura livre de doenças (COLLARD , 2000).

Considerando a necessidade de se desenvolver tecnologias adequadas ao manejo agroecológico de hortaliças e de se conhecer a sua eficiência e modo de ação, o presente trabalho teve como objetivo testar o efeito de antibiose do Agrobio contra Xanthomonas campestris pv. vesicatoria in vitro, seu efeito no controle da mancha bacteriana da cultura do pimentão e sobre o desenvolvimento das mudas, em condições de casa de vegetação.

\section{MATERIAL E MÉTODOS}

O trabalho foi efetuado em duas etapas, com testes de antibiose in vitro e bioensaios em casa de vegetação. Para testar o efeito de antibiose do biofertilizante Agrobio foram feitos bioensaios com três isolados diferentes de Xanthomonas $\boldsymbol{c}$. pv. vesicatoria, in vitro. No primeiro bioensaio utilizouse o isolado ENA 4170 da bactéria e o Agrobio a 5\% com três datas de fabricação diferentes, 35 dias (em preparo), 85 e 115 dias (prontos para uso), e submetidos a três tratamentos, Agrobio original, esterilizado em Milipore $(0,22 \mathrm{~mm})$ e autoclavado $\left(120^{\circ} \mathrm{a} 20 \mathrm{~min}\right)$. Os tratamentos testado foram: sulfato de estreptomicina $\left(0,24 \mathrm{mg} \mathrm{mL}^{-1}\right)$; sulfato de cobre (0,24 $\left.\mathrm{mg} \mathrm{mL}^{-1}\right)$; Agrobio em uso filtrado; Agrobio em espera autoclavado; Agrobio em uso autoclavado; Agrobio em espera filtrado; Agrobio em preparo filtrado; Agrobio em preparo autoclavado; Agrobio em espera original; Agrobio em uso original; Agrobio em preparo original; água; aplicados ao método de escavação em placa (AGUIAR, 1997) e delineamento inteiramente ao acaso com 12 tratamentos e cinco repetições. Em placas de Petri de $20 \mathrm{~cm}$ de diâmetro contendo 50ml de meio Nutriente Agar (MANUAL MERCK, 1982), foram distribuídos $500 \mathrm{ml} \mathrm{de}$ suspensão bacteriana em solução salina $(\mathrm{NaCl} / 0,85 \%)$ ajustada em espectrofotômetro para $75 \%$ de transmitância, a 600nm. Após secagem do líquido excedente foram feitos seis orifícios de $5 \mathrm{~mm}$ de diâmetro onde foram adicionados $25 \mathrm{ml}$ de amostras dos respectivos tratamentos. A leitura dos resultados foi feita após 48 horas de incubação a $28^{\circ} \mathrm{C}$, medindose o halo de inibição formado ( $\mathrm{mm}$ ).Em um segundo bioensaio, utilizou-se o mesmo procedimento, porém com o isolado ENA 4370 de $\boldsymbol{X}$. campestris pv. vesicatoria, e comparou-se apenas o Agrobio com as mesmas datas de fabricação citadas anteriormente e submetido a três preparos (original, autoclavado e esterilizado em Milipore). Neste, porém, adotou-se o delineamento inteiramente ao acaso, em esquema fatorial $(3 \times 3)$, três datas de fabricação do produto e preparações, também com cinco repetições.

No terceiro bioensaio, avaliou-se apenas o Agrobio pronto para uso (56 dias) a $5 \%$ e o isolado ENA 818 de $\boldsymbol{X}$. campestris pv. vesicatoria. Compararam-se seis tratamentos, Agrobio na forma original, filtrado em Milipore, autoclavado e três testemunhas, água, sulfato de cobre $\left(0,24 \mathrm{mg} \mathrm{mL}^{-1}\right) \mathrm{e}$ sulfato de estreptomicina $\left(0,24 \mathrm{mg} \mathrm{mL}^{-1}\right)$ em delineamento de blocos ao acaso com cinco repetições e a mesma metodologia citada no bioensaio anterior.

Para testar o efeito do produto sobre mudas de pimentão e sobre o controle da mancha bacteriana, foram realizados dois bioensaios simultâneos em condições de casa de vegetação. Os bioensaios foram conduzidos no setor de Horticultura do Departamento de Fitotecnia, da Universidade Federal Rural do Rio de Janeiro, no período de setembro a outubro de 2001. Sementes de pimentão das variedades, Cascadura Ikeda e Cascadura Itaipu, foram semeadas em bandejas de isopor com substrato comercial. Logo após a emergência, as mudas de duas bandejas foram inoculadas por atomização com o isolado ENA 818 de $\boldsymbol{X}$. campestris pv. vesicatoria. Utilizou-se suspensão em solução salina $(\mathrm{NaCl}$ a $0,85 \%)$ a partir de cultura com $48 \mathrm{~h}$ de crescimento a $28^{\circ} \mathrm{C}$ e a concentração final ajustada para $75 \%$ de transmitância a 600nm. Após o aparecimento dos sintomas foram transplantadas três mudas de cada uma das duas variedades para as outras bandejas, quando então iniciaram-se as aplicações dos tratamentos. Inicialmente, compararam-se quatro tratamentos: sulfato de estreptomicina $\left(0,24 \mathrm{mg} \mathrm{mL}^{-1}\right)$ sulfato de cobre $\left(0,24 \mathrm{mg} \mathrm{mL}^{-1}\right)$, Agrobio $(5 \% \mathrm{v} / \mathrm{v})$ e como testemunha água, pulverizados semanalmente em um total de quatro aplicações. Adotou-se o delineamento inteiramente ao acaso com cinco repetições, e cada parcela era composta por meia bandeja de isopor de $8 \times 16$ células.

Paralelamente, compararam-se quatro apresentações do biofertilizante e duas formas diferentes de aplicação, uma via foliar e a outra via raiz. O Agrobio, diluído a 5\% em água destilada, foi previamente submetido aos seguintes preparos: 
Agrobio original filtrado em papel; Agrobio autoclavado $\left(120^{\circ}\right.$ a $\left.20 \mathrm{~min}\right)$ filtrado em papel; Agrobio esterilizado em Milipore $(0,22 \mathrm{~mm}$ de diâmetro) e fração retida no filtro Milipore, diluída em água destilada. Foram realizadas quatro pulverizações na parte aérea e a aplicação via substrato foi feita pela imersão das bandejas na calda até absorção completa do líquido. O delineamento experimental utilizado foi o inteiramente ao acaso, em esquema fatorial $2 \times 4$, duas formas de aplicação e quatro apresentações do produto (original, autoclavado, filtrado em Milipore e fração retida na filtragem), com quatro repetições.

As avaliações foram efetuadas ao final do bioensaio, quando as mudas atingiram o ponto de transplante, cerca de seis semanas após o semeio. Primeiramente, foram contados o número total de mudas por parcela e o número de mudas com sintomas da doença, logo após 20 mudas por parcela que foram coletadas e submetidas às seguintes avaliações: matéria fresca, seca e altura da parte aérea e também o comprimento e matéria seca das raízes. Destas tomaram-se cinco plantas, das quais se mediu a área foliar pelo método descrito por AGUIAR (1997) e 15 foram secas e moídas para determinação do matéria seca e análise de macro e micronutrientes nas folhas e raízes (SILVA, 1999).

Os dados obtidos em cada um dos bioensaios foram analisados separadamente pelo teste F e teste de Tukey a 5\%, para comparação das médias. Os dados relativos ao desenvolvimento das mudas pulverizadas com diferentes apresentações de Agrobio foram, ainda, submetidos à análise de Correlação de Pearson.

\section{RESULTADOS E DISCUSSÃO}

O Agrobio apresentou atividade bacteriostática sobre $X$. campestris pv. vesicatoria para os três isolados testados (Tabela 1) independente da data de fabricação e do tratamento aplicado ao produto. Como a filtragem e a autoclavagem não reduziram o tamanho do halo de inibição, pode-se afirmar que a ação bacteriostática do produto deve-se à presença de substâncias bactericidas ou bacteriostáticas no mesmo e não somente a ação direta da flora microbiana e, que estas substâncias estão presentes no produto independente da idade do mesmo (36 a 100 dias), não sendo termolábeis (Tabela 1). Apesar dos bioensaios terem sidos feitos separadamente, notou-se uma pequena variação entre os isolados quanto à sensibilidade aos produtos testados.
Tabela 1 - Inibição do crescimento de Xanthomonas campestris. pv. vesicatoria (Isolado ENA 4170) in vitro, expresso pelo diâmetro do halo de inibição (mm) formado. Seropédica, RJ, 2001.

\begin{tabular}{|c|c|c|}
\hline \multirow[t]{3}{*}{ Tratamento } & \multirow{2}{*}{$\begin{array}{c}\text { Isolado } \\
\text { ENA } 4170\end{array}$} & Isolado \\
\hline & & ENA 4370 \\
\hline & \multicolumn{2}{|c|}{ Halo de inibição (mm) } \\
\hline $\begin{array}{l}\text { Sulfato de estreptomicina } \\
\left(0,24 \mathrm{mg} \mathrm{m}^{-1}\right)\end{array}$ & $17,16 \mathrm{Aa}$ & 20,36 Аa \\
\hline Sulfato de cobre $\left(0,24 \mathrm{mg} \mathrm{ml}^{-1}\right)$ & $12,66 \mathrm{Bb}$ & $12,51 \mathrm{Bb}$ \\
\hline Agrobio em uso filtrado & $8,44 \mathrm{Bb}$ & $5,00 \mathrm{Cd}$ \\
\hline Agrobio em espera autoclavado & $8,27 \mathrm{Bb}$ & 7,33 Cc \\
\hline Agrobio em uso autoclavado & $8,22 \mathrm{Bb}$ & $8,55 \mathrm{Bc}$ \\
\hline Agrobio em espera filtrado & $7,94 \mathrm{Bc}$ & $7,94 \mathrm{Bc}$ \\
\hline Agrobio em preparo filtrado & $7,72 \mathrm{Bc}$ & $8,44 \mathrm{Bc}$ \\
\hline Agrobio em preparo autoclavado & $7,38 \mathrm{Cc}$ & $8,38 \mathrm{Bc}$ \\
\hline Agrobio em espera original & $6,83 \mathrm{Cc}$ & $8,16 \mathrm{Bc}$ \\
\hline Agrobio em uso original & $6,33 \mathrm{Cc}$ & $7,61 \mathrm{Cc}$ \\
\hline Agrobio em preparo original & $5,72 \mathrm{Cc}$ & $8,82 \mathrm{Bc}$ \\
\hline Água & $0,00 \mathrm{Dd}$ & $0,00 \mathrm{De}$ \\
\hline Média geral & 8,09 & 8,59 \\
\hline $\mathrm{CV} \%$ & 25,0 & 20,0 \\
\hline
\end{tabular}

* médias não seguidas da mesma letra, maiúscula na linha e minúscula na coluna, diferem estatisticamente pelo teste de Tukey em 5\% de probabilidade de erro.

A análise foliar não revelou diferenças entre os tratamentos quanto aos teores de macronutrientes, que permaneceram sempre dentro da faixa ideal para plantas de pimentão (SILVA, 1999), porém diferenças quanto aos teores de cobre (100x) e boro foi duas vezes maior nas parcelas pulverizadas com sulfato de cobre e Agrobio. O biofertilizante Agrobio, apesar de menos eficiente em reduzir a incidência da doença, permitiu uma maior retenção das folhas infectadas o que provavelmente contribuiu para o maior desenvolvimento das mudas. A análise foliar, no entanto, foi feita a partir de uma amostra composta de plantas coletadas nas quatro repetições e, portanto, não foi feita a análise estatística para avaliar o efeito nutricional dos tratamentos.

Pelos resultados, pode-se afirmar que o Agrobio melhorou o desenvolvimento das mudas, expresso pela maior altura, matéria seca da raiz e parte aérea e área foliar (Tabela 2) tanto por reduzir o desenvolvimento da mancha-bacteriana devido a sua ação bacteriotática quanto por reduzir a taxa de desfolha. Esta doença caracteriza-se por promover a abscisão prematura de folhas infectadas, reduzindo a área foliar das plantas. Isto pode ser confirmado pela análise de correlação 
Tabela 2 - Interação entre diferentes apresentações do Agrobio e o local de aplicação, foliar ou aplicado diretamente no substrato, sobre a altura e matéria seca de parte aérea de mudas de pimentão. Seropédica, RJ, 2001.

\begin{tabular}{lllll}
\hline Produto & \multicolumn{2}{l}{ Altura $(\mathrm{cm})$} & & \multicolumn{2}{l}{$\begin{array}{l}\text { Matéria seca parte aérea } \\
(\mathrm{g})\end{array}$} \\
\cline { 2 - 6 } & Foliar & Solo & Foliar & Solo \\
\hline Agrobio original & $17,79 \mathrm{Aa}$ & $13,88 \mathrm{Ba}$ & $0,745 \mathrm{Aa}$ & $0,610 \mathrm{Ba}$ \\
Agrobio autoclavado & $13,68 \mathrm{Ab}$ & $13,65 \mathrm{Aa}$ & $0,555 \mathrm{Ab}$ & $0,525 \mathrm{Aab}$ \\
Agrobio filtrado & $17,65 \mathrm{Aa}$ & $14,14 \mathrm{Ba}$ & $0,725 \mathrm{Aab}$ & $0,575 \mathrm{Ba}$ \\
Agrobio retido no filtro & $12,45 \mathrm{Ac}$ & $11,03 \mathrm{Bb}$ & $0,555 \mathrm{Ab}$ & $0,450 \mathrm{Bb}$ \\
Média geral & 15,39 & 13,17 & 0,645 & 0,540 \\
CV \% & 2,37 & \multicolumn{4}{c}{9,15} \\
\hline
\end{tabular}

* médias não seguidas da mesma letra, maiúscula na linha e minúscula na coluna, diferem estatisticamente pelo teste de Tukey em 5\% de probabilidade de erro. campestris pv. vesicatoria. O melhor desenvolvimento das plantas e a redução das infecções pela fitobactéria são resultados de uma interação complexa envolvendo provavelmente um conjunto de fatores, podendo-se incluir entre estes a ação antibiótica dos metabólitos produzidos pelos microrganismos durante o seu processo de fabricação, competição microbiana no filoplano e efeitos nutricionais ou promotores de crescimento, constatado principalmente pela maior retenção das folhas infectadas.

\section{AGRADECIMENTOS}

À CAPES pela concessão da bolsa de Mestrado a (Tabela 3). Observou-se, no segundo bioensaio em casa de vegetação, a correlação negativa, alta e significativa, entre a incidência da doença e a altura das plantas $(-0,87)$, peso seco de parte aérea $(-0,80)$ e área foliar $(-0,87)$. Já no primeiro bioensaio, o Agrobio, apesar de apresentar significativamente maior incidência da doença que os tratamentos de sulfato de estreptomicina e de sulfato de cobre, proporcionou também maior desenvolvimento, significativo estatisticamente, das mudas (Tabela 2).

\section{CONCLUSÕES}

O biofertilizante Agrobio apresentou efeito benéfico ao desenvolvimento das mudas de pimentão e ação bacteriostática sobre $\boldsymbol{X}$.

Tabela 3 - Coeficiente de correlação de Pearson (r) entre as diferentes variáveis analisadas em mudas de pimentão, cultivar Cascadura Itaipu, pulverizadas semanalmente com Agrobio, em condições de casa de vegetação. Seropédica, RJ, 2001.

\begin{tabular}{lcccccc}
\hline Variável & ATM & MSPA & MSR & IMB & PM & AF \\
\hline $\begin{array}{l}\text { Altura das mudas } \\
\text { (ATM) }\end{array}$ & 1,00 & & & & & \\
$\begin{array}{l}\text { Matéria seca de parte } \\
\text { aérea (PSPA) }\end{array}$ & 0,89 & 1,00 & & & & \\
$\begin{array}{l}\text { Matéria seca de raiz } \\
\text { (PSR) }\end{array}$ & 0,66 & 0,60 & 1,00 & & & \\
$\begin{array}{l}\text { Incidência de mancha } \\
\text { bacteriana \% (IMB) }\end{array}$ & $-0,87$ & $-0,80$ & - & 1,00 & & \\
$\begin{array}{l}\text { Plantas mortas (PM) } \\
\text { Área foliar (AF) }\end{array}$ & $-0,59$ & - & - & 0,67 & 1,00 & \\
\hline
\end{tabular}

* valores de r significativos até $5 \%$. primeira autora, ao CNPq e à FAPERJ pelo financiamento do projeto.

\section{REFERÊNCIAS BIBLIOGRÁFICAS} de Xanthomonas c.pv. vesicatoria, resistentes ao cobre e perspectivas de seu controle com formulações cúpricas e cuprorgânicas. 1997. 153f. Dissertação (Mestrado em Fitotecnia) - Curso de Pós-graduação em Fitotecnia, Universidade Federal Rural do Rio de Janeiro.

COLLARD, F.H. Efeito do uso do biofertilizante Agrobio em maracujazeiro amarelo, Seropédica, RJ, 2000. In: CONGRESSO BRASILEIRO DE FRUTICULTURA, 2000. Taubaté, SP. Anais... Taubaté : Universidade de Taubaté, 2000. p. 16.

FERNANDES, M. do C. de A. O biofertilizante Agrobio. Informativo do Centro Nacional de Pesquisa de Agrobiologia, ano 4, n.13, p.1-16, Set, 2000.

FERNANDES, M. do C. de A. et al. Cultivo protegido do tomateiro sob manejo orgânico. Informativo do Centro Nacional de Pesquisa de Agrobiologia, ano 4, n.13, p.17-22, Set, 2000.

MERCK, E. Manual Merck de preparo de meios de cultura. Frankfurt : Dürst, 1982. 124p.

Pinheiro, S.; BARRETO, S.B. MB-4 Agricultura sustentável, trofobiose e biofertilizantes. Blumenau : Cooperativa Ecológica Colméia - MIBASA, 1996. 280 p.

SANTOS, A.C.V. dos. Biofertilizante líquido: o defensivo agrícola da natureza. Niterói : EMATER-RIO, 1992. $16 \mathrm{p}$.

SILVA, F.C. da. Manual de análises químicas de solos, plantas e fertilizantes. Brasília : EMBRAPA, 1999. 370p.
AGUIAR, L.A. Identificação de isolados nacionais 